\title{
Bladder rupture after voiding cystourethrography: A case report and literature review on piffalls and bladder volume estimation
}

\author{
Sorena Keihani, MD; Abdol-Mohammad Kajbafzadeh, MD \\ Pediatric Urology Research Center, Pediatric Center of Excellence, Tehran University of Medical Sciences, Tehran, Islamic Republic of Iran
}

Cite as: Can Urol Assoc J 2015;9(11-12):E826-9. http://dx.doi.org/10.5489/cuaj.3234

Published online November 4, 2015.

\section{Abstract}

Voiding cystourethrography (VCUG) is a common diagnostic study in pediatric urology. Although generally considered a safe procedure, VCUG can incur some complications. Bladder rupture following VCUG is a very rare complication and mostly happens in the setting of unused bladders, previous surgeries, or underlying disease. The rupture is almost always intraperitoneal needing prompt surgical treatment. We present a unique case of extraperitoneal bladder rupture after VCUG in an 8-month-old boy. The rupture remained unnoticed and the patient recovered spontaneously without medical or surgical intervention. To the best of our knowledge, this is the first such case report in the English literature. The information provided may guide clinicians on the proper use of bladder volume formulas in children and also help them in getting a proper VCUG study.

\section{Introduction}

Voiding cystourethrography (VCUG) is a common diagnostic procedure in pediatric urology. Although VCUG is generally safe, rare but serious complications may occur during or after VCUG. ${ }^{1}$ Different factors like patient age, underlying diseases, chronic conditions, and imaging technique are important factors in obtaining a safe VCUG. We report a unique case of neglected extraperitoneal bladder rupture after VCUG; the patient healed spontaneously with no medical or surgical intervention. We also reviewed the literature on bladder rupture after VCUG in children with no known chronic underlying disease with a focus on bladder capacity estimation and the VCUG methods used.

\section{Case report}

After multiple episodes of urinary tract infections, VCUG was performed on an 8-month-old boy at a district private radiology center. He was born at 30-weeks gestation by Cesarean section due to maternal pre-eclampsia with a birth weight of 1280 grams. He was admitted to neonatal intensive care unit after birth. He was otherwise healthy, with a weight of 6200 grams at the time of the VCUG. A radiology technician performed the study without supervision of a physician. A Foley catheter was used with the balloon inflated in the bladder. Contrast material was prepared by diluting the contrast medium with saline, according to the recipe and about $60 \mathrm{~mL}$ of contrast material was manually instilled using a $60-\mathrm{mL}$ syringe. Extravasation of contrast material remained unnoticed during the imaging and the study was completed after obtaining post-voiding views. The child had no fever and was asymptomatic, except for a transient hematuria at home (lasting less than 24 hours) and the parents did not seek medical advice. On reviewing the VCUG 4 days after the procedure, the physician noted perivesical extravasation of contrast material extending to the extraperitoneal space and a bilateral vesicoureteral reflux (Fig. 1).

The child underwent an additional VCUG on the fifth day that did not show any extravasation of contrast material (Fig. 2). He was referred to our tertiary centre for further workup. Abdominal x-ray and ultrasound studies were normal. No surgical or medical intervention was needed given the time lapse and since the child was asymptomatic. Abdominal x-ray and ultrasound studies were also normal, with no evidence of urinoma or collections 1 month after the procedure.

\section{Discussion}

Non-traumatic bladder rupture in children is rare and almost always happens in the setting of chronic unused bladders, previous surgeries, or underlying disease. ${ }^{2}$ Besides the uncommon, although serious, complications of VCUG like sepsis and hypersensitivity to contrast medium, ${ }^{2}$ bladder rupture may lead to devastating and life-threatening complications especially in patients with underlying conditions, such 


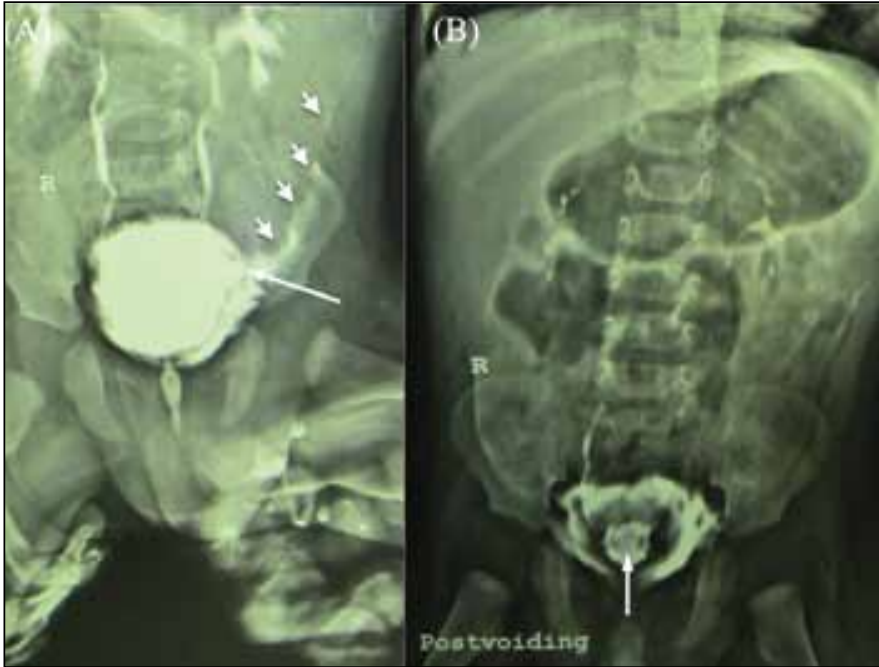

Fig. 1. (A) Initial voiding cystourethrography showing bilateral vesicoureteral reflux, also extraperitoneal contrast material (short arrows) and the possible site of rupture (long arrow). (B) Post-voiding view depicting filled balloon of the catheter (long arrow) and also perivesical contrast material.

as chronic unused bladders and spina bifida. For example, reflux of contrast material via ventriculoperitoneal shunt has been reported after intraperitoneal bladder rupture during VCUG, leading to severe neurological toxicity. ${ }^{3}$ Bladder rupture during VCUG in an otherwise healthy child is even rarer. ${ }^{4-11}$ To the best of our knowledge, this is the first reported case of an asymptomatic extraperitoneal bladder rupture with spontaneous healing.

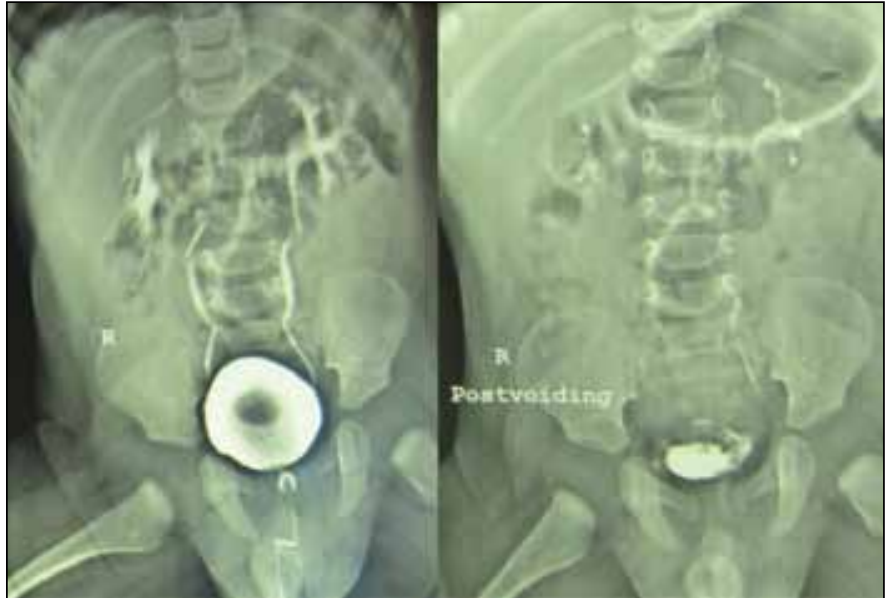

Fig. 2. Voiding cystourethrography five days after bladder rupture shows bilateral grade III reflux with no leakage of contrast material. The balloon of the Foley catheter is seen in the bladder.

Using a Foley catheter with the balloon inflated in bladder was the first pitfall in this case. The balloon may have obstructed the bladder neck and prevented urine leakage if the pressure and volume was beyond the bladder endurance. ${ }^{5}$ A $5-\mathrm{F}$ feeding tube is recommended for children $<1$ year of age and an 8-F feeding tube may be used in older children. ${ }^{2}$ Additionally, the contrast material should be instilled using the gravity method with the container placed no higher than $60 \mathrm{~cm}$ above the patient's level. ${ }^{5}$ Manual instillation (as happened in this case) should be avoided due to risk of rapid pressure increase and consequent bladder

\begin{tabular}{|c|c|c|c|c|c|c|c|}
\hline \multirow[t]{2}{*}{ No. } & \multirow[t]{2}{*}{ Reference } & \multirow[t]{2}{*}{ Age and sex } & \multicolumn{3}{|c|}{ VCUG method } & \multirow[t]{2}{*}{ Type of rupture } & \multirow[t]{2}{*}{ Treatment } \\
\hline & & & $\begin{array}{l}\text { Catheter } \\
\text { type }\end{array}$ & $\begin{array}{l}\text { Instillation } \\
\text { method }\end{array}$ & Volume & & \\
\hline 1 & $\begin{array}{l}\text { Crowley and } \\
\text { McAlister } 1995^{4}\end{array}$ & 4.5 years, $F$ & $8 \mathrm{~F}$ feeding & Gravity method & $220 \mathrm{~mL}$ & $\begin{array}{l}\text { Extravasation to bladder } \\
\text { wall and perivesical tissue }\end{array}$ & $\begin{array}{l}\text { Antibiotics and } \\
\text { antispasmodics }\end{array}$ \\
\hline 2 & $\begin{array}{l}\text { Wosnitzer et al. } \\
2005^{5}\end{array}$ & 90 days, $F$ & $5 \mathrm{~F}$ feeding & Manual (syringe) & NM & Intraperitoneal & $\begin{array}{c}\text { Open surgery, catheter } \\
\text { drainage }\end{array}$ \\
\hline 3 & Cam $2006^{6}$ & 4 months, M & NM & NM & NM & $\begin{array}{l}\text { Intraperitoneal (anterior } \\
\text { wall) }\end{array}$ & Open surgery \\
\hline 4 & $\begin{array}{l}\text { Kajbafzadeh et } \\
\text { al. } 2007^{7}\end{array}$ & 20 days, $M$ & $6 \mathrm{~F}$ feeding & Manual (syringe) & $60 \mathrm{~mL}$ & $\begin{array}{c}\text { Intraperitoneal (bladder } \\
\text { dome) }\end{array}$ & $\begin{array}{l}\text { Open surgery, } \\
\text { suprapubic tube }\end{array}$ \\
\hline 5 & $\begin{array}{l}\text { Kajbafzadeh et } \\
\text { al. } 2007^{7}\end{array}$ & 9 months, $\mathrm{F}$ & $8 \mathrm{~F}$ feeding & Manual (syringe) & $100 \mathrm{~mL}$ & $\begin{array}{l}\text { Intraperitoneal (bladder } \\
\text { dome) }\end{array}$ & $\begin{array}{c}\text { Open surgery, catheter } \\
\text { left in place }\end{array}$ \\
\hline 6 & Lim et al. $2007^{* *}$ & 18 months & 6 F Foley & Manual (syringe) & $100 \mathrm{~mL}$ & Intraperitoneal & Open surgery \\
\hline 7 & Lim et al. $2007^{* *}$ & 6 weeks & $6 \mathrm{~F}$ feeding & Manual (syringe) & $50 \mathrm{~mL}$ & $\begin{array}{c}\text { Intraperitoneal (bladder } \\
\text { dome) }\end{array}$ & Open surgery \\
\hline 8 & $\begin{array}{l}\text { Khavari et al. } \\
2010^{9}\end{array}$ & 29 months, $\mathrm{F}$ & $8 \mathrm{~F}$ feeding & Gravity method & $325 \mathrm{~mL}$ & Extraperitoneal & $\begin{array}{l}\text { Non-operative, 48-hour } \\
\text { catheter drainage }\end{array}$ \\
\hline 9 & $\begin{array}{l}\text { Oktar et al. } \\
2011^{10}\end{array}$ & 8 years, $F$ & NM & Manual (syringe) & NM & $\begin{array}{c}\text { Intraperitoneal (bladder } \\
\text { dome) }\end{array}$ & Laparoscopic repair \\
\hline 10 & Lee et al. $2012^{11}$ & 9 months, $\mathrm{F}$ & 5 F Foley & Manual (syringe) & $80 \mathrm{~mL}$ & $\begin{array}{l}\text { Intraperitoneal (left bladder } \\
\text { wall) }\end{array}$ & Open surgery \\
\hline
\end{tabular}


Keihani and Kajbafzadeh

\begin{tabular}{|c|c|c|c|}
\hline Reference & Patients & Measurement method & Bladder capacity formula* \\
\hline Koff $1983^{12}$ & $0-24$ years old & Cystometry under general anesthesia & $($ Age $[y]+2) \times 30$ \\
\hline Kaefer et al. $1997^{13}$ & $0-24$ years old & Radionuclide cystography & $($ Age $[y]+1) \times 60$. OR $(2 \times$ Age $[y]+2) \times 30$ \\
\hline Hjalmas $1988^{14}$ & $0-14$ years old & Urodynamic (expert opinion) & $($ Age $[y]+1) \times 30$ \\
\hline Fairhurst et al. $1991^{15}$ & $0-12$ years old & Cystourethrography (manual injection) & $(7 \times$ Weight $[\mathrm{kg}])-1.2$. OR $(1.5 \times$ L1-3 $[\mathrm{mm}])-34.2$ \\
\hline Holmdahl et al. $1996^{16}$ & 0-12 months old & 4-hour voiding observation & $(2.5 \times$ Age $[$ months] $)+38$ \\
\hline Chung et al. $2013^{17}$ & 0-24 months old & $\begin{array}{l}\text { 2-day volume chart and 4-hour voiding } \\
\text { observation }\end{array}$ & $(1.6 \times$ Age $[$ months $])+45$ OR $(4.1 \times$ Weight $[\mathrm{kg}])+28$ \\
\hline
\end{tabular}

${ }^{*}$ All volumes are in milliliters $(\mathrm{mL})$, for volume formulas originally in ounces (oz.) a multiplier of 30 is used to convert to $\mathrm{mL}$.

rupture..$^{5,7}$ The dome of the bladder is the weakest part, ${ }^{11}$ and most of the previously reported cases suffered a rupture in the dome area and all (except one ${ }^{9}$ ) had intraperitoneal bladder rupture necessitating surgical intervention (Table 1). However, in our case the rupture was extraperitoneal and most probably happened through a weak point at left side of the bladder wall (Fig. 1, part A, long arrow).

While most children with intraperitoneal bladder rupture will need open or laparoscopic surgery, the management of extraperitoneal bladder rupture should be individualized. ${ }^{9}$ Minimal signs and symptoms are expected due to the absence of peritoneal irritation. Conservative and non-invasive treatment by placing the urethral catheter with appropriate follow-up is usually enough to treat extraperitoneal bladder rupture in the absence of concomitant injuries. ${ }^{9}$

Although the bladder volume is well-studied in adults and older children, few studies have addressed this parameter in infants and children $<2$ years of age (Table 2). ${ }^{12-17}$ Recently, Costa and colleagues ${ }^{18}$ suggested that most formulas overestimate bladder capacity in infants. Using urodynamic data, they showed that the mean bladder capacity is about $48.9 \mathrm{ml}$ in a 9-month-old infant - less than half the volume calculated using common formulas for this age. ${ }^{18}$ This may also be the case in our patient since $60 \mathrm{~mL}$ of contrast material was instilled during the first VCUG. According to the formulas specific for children under a year old ${ }^{14-17}$ (Table 2), the estimated bladder capacity in our case would be as low as $42.2 \mathrm{~mL}$ (Fairhurst formula ${ }^{15}$ ) and up to $58 \mathrm{~mL}$ (Holmdahl formula $\left.{ }^{16}\right)$. However, using formulas proposed by Koff ${ }^{12}$ and Keafer and colleagues ${ }^{13}$ would largely overestimate these values $(80-100 \mathrm{~mL})$. This highlights the importance of precise bladder capacity estimation in younger infants. Additionally, age-based formulas may overestimate bladder capacity in young infants, specifically in patients born prematurely with lower birth weights. Therefore, using weight-based formulas may be more appropriate. Ideally sex-specific weight and age-based charts should be available to estimate bladder capacity in children. As proposed by Martinez-Garcia and colleagues, ${ }^{19,20}$ we also believe that the bladder is not like a "rigid vase" with a specific and constant capacity. The setting in which the bladder capacity formulas are calculated in different studies (e.g., under anesthesia, during natural void- ing, or based on urodynamic study) is also important since the presence of a catheter in the bladder and the stressful stimuli may lead to decreased bladder capacity compared to a relaxed bladder. ${ }^{21}$

\section{Conclusions}

Pediatric urologists and radiologists should pay attention to the setting in which VCUG is performed, and assess the risk of overestimating bladder capacity. Additionally, conditions like hutch diverticula may remain undiagnosed in an otherwise healthy child until the VCUG is performed. Moreover, a large volume instilled in the bladder may increase the risk of bladder rupture in these cases.

Competing interests: The authors declare no competing financial or personal interests.

This paper has been peer-reviewed.

\section{References}

1. McAlister WH, Cacciarelli A, Shackelford GD. Complications associated with cystography in children. Radiology 1974;111:167-72. http://dx.doi.org/10.1148/111.1.167

2. Agrawalla $S$, Pearce R, Goodman TR. How to perform the perfect voiding cystourethrogram. Pediatr Radiol 2004;34:114-9. http://dx.doi.org/10.1007/s00247-003-1073-8

3. Dalkin B, Franco I, Reda EF, et al. Contrast-induced central nervous system toxicity after radiographic evaluation of the lower urinary tract in myelodysplastic patients with ventriculoperitoneal shunts. I Urol 1992;148:120-1.

4. Crowley JJ, McAlister WH. Extravasation of contrast material during voiding cystourethrography. Abdom Imaging 1995;20:68-9. http://dx.doi.org/10.1007/BF00199649

5. Wosnitzer $M$, Shusterman $D$, Barone JG. Bladder rupture in premature infant during voiding cystourethrography. Urology 2005;66:432. http://dx.doi.org/10.1016/j.urology.2005.02.016

6. Cam H. Bladder rupture following voiding cystourethrography. Indian Pediatr 2006;43:179-80.

7. Kajbafzadeh AM, Saeedi P, Sina AR, et al. Infantile bladder rupture during voiding cystourethrography. Int Braz J Urol 2007;33:532-5; discussion 535. http://dx.doi.org/10.1590/S167755382007000400012

8. Lim JH, Jeon SB, Park JS, et al. Bladder rupture during voiding cystourethrography. Korean J Urol 2007;48:230-2. http://dx.doi.org/10.4111/kju.2007.48.2.230

9. Khavari R, Bayne AP, Roth DR. A report of an iatrogenic bladder rupture in a normal healthy child during voiding cystourethrography. Urology 2010;75:684-6. http://dx.doi.org/10.1016/i.urology.2009.06.005

10. Oktar $\mathrm{T}$, Sanli 0 , Atar A, et al. latrogenic bladder rupture in a child following voiding cystourethrography and its laparoscopic management. Eur J Pediatr Surg 2011;21:275-7. http://dx.doi. org/10.1055/s-0031-1277132 
11. Lee KO, Park SJ, Shin Jl, et al. Urinary bladder rupture during voiding cystourethrography. Korean J Pediatr 2012;55:181-4. http://dx.doi.org/10.3345/kip.2012.55.5.181

12. Koff SA. Estimating bladder capacity in children. Urology 1983;21:248. http://dx.doi. org/10.1016/0090-4295(83)90079-1

13. Kaefer M, Zurakowski D, Bauer SB, et al. Estimating normal bladder capacity in children. J Urol 1997;158:2261-4. http://dx.doi.org/10.1016/S0022-5347(01)68230-2

14. Hialmas K. Urodynamics in normal infants and children. Scand J Urol Nephrol Suppl 1988; 1 14:20-7.

15. Fairhurst JJ, Rubin CM, Hyde I, et al. Bladder capacity in infants. J Pediatr Surg 1991;26:55-7. http:// dx.doi.org/10.1016/0022-3468(91)90426-T

16. Holmdahl $G$, Hanson $E$, Hanson $M$, et al. Four-hour voiding observation in healthy infants. J Urol 1996;156:1809-12. http://dx.doi.org/10.1016/S0022-5347(01)65543-5

17. Chung JM, Kim KS, Kim SO, et al. Evaluation of bladder capacity in Korean children younger than 24 months: A nationwide multicenter study. World I Urol 2013;31:225-8. http://dx.doi.org/10.1007/ s00345-011-0762-4

18. Costa DFG, Lavallée LT, Dubois C, et al. Are we accurately predicting bladder capacity in infants less than one year of age? Can Urol Assoc J 2014;8:329-32. http://dx.doi.org/10.5489/cuaj.2102
19. Martinez-Garcia R, Ubeda-Sansano MI, Diez-Domingo J, et al. It is time to abandon «expected bladder capacity.» Systematic review and new models for children's normal maximum voided volumes. Neurourol Urodyn 2014;33:1092-8. http://dx.doi.org/10.1002/nau.22452

20. Martinez-Garcia R: Author's response re: letter to the editor re: Martinez-Garcia R, Ubeda-Sansano MI, Diez-Domingo J, et al. It is time to abandon "expected bladder capacity." Systematic review and new models for children's normal maximum voided volumes. Neurourol Urodyn 2013;33:1099-100.

21. Franco I. What is an appropriate urodynamic bladder capacity in infants? Can Urol Assoc J 2014;8:333. http://dx.doi.org/10.5489/cuaj.2296

Correspondence: Dr. A.M. Kajbafzadeh, Pediatric Urology Research Center, Pediatric Center of Excellence, No.62, Dr. Gharib's Street, Keshavarz Blvd, Tehran, Islamic Republic of Iran, PO Box: 1419733151; kaibafzd@sina.tums.ac.ir 